\title{
Research on hierarchical method for extraction ground fissures through high resolution image
}

\author{
X.H. Zhang a $\underline{\text { L. Zhu }}^{\text {a }}$, W. Wang ${ }^{\text {b }}$, X.J. Li ${ }^{\text {a }}$, L.S. Meng ${ }^{b}$ and D. Meng ${ }^{\text {a }}$ \\ ${ }^{a}$ Laboratory Cultivation Base of Environment Process and Digital Simulation, College of Resource \\ Environment and Tourism, Capital Normal University, Beijing, P.R. China \\ ${ }^{b}$ Laboratory of Non-fossil Energy Minerals, Tianjin Center of China Geological Survey, Tianjin, P.R. China
} Email: hi-zhulin@163.com

\begin{abstract}
Earth fissures have been observed in hundreds of areas worldwide but their automatic detection is still a challenge. The use of remote sensing technology can effectively extract the information of ground fissures. Its application is of great utility especially in places hardly accessible to the in-situ reconnaissance, such as in coal-mining regions, where the monitoring of ground fissures is absolutely necessary to guarantee the safety of the mining operations. One of the most limits to the use of the automatic extraction of ground fissures by remote sensing is the low precision of the results. Aiming at this problem, this paper proposes a hierarchical extraction method to improve the accuracy of ground fissure automatic extraction on the basis of the GeoEye-1 optical images. Firstly, the image is segmented to set adjacent pixels as one object. According to the spectral and geometric characteristics of segmentation object, surface cover obviously different with the ground fissures are removed by mask tool. Then, the linear objects are extracted through the method of canny edge detection and the left surface cover is removed. Finally, the fractal characteristics of linear objects are calculated to distinguish the ground fissures from other linear surface factors. A coal-mining region of northeastern Ordos was chosen as a case test area to detect the validity of the proposed method. The results show that the method is better than the traditional method to extract ground fissures. The overall accuracy of the proposed method is $85.7 \%$, while that of traditional supervised classification only $57.1 \%$.
\end{abstract}

Keywords: GeoEye image, ground fissures, hierarchical extraction method, feature extraction 


\section{INTRODUCTION}

At present, the investigation methods of ground fissures mainly include traditional field investigation and remote sensing-based technology. Field investigation method has a high precision, but it takes a lot of time, manpower, and material resources. Conversely, the ground fissure monitoring based on remote sensing technology is relatively fast and efficient even if it also has various limitations, among all the low accuracy of the products. In order to provide some examples, some key studies are listed in the following.

Zhao (2009) established a knowledge model to extract the ground fissure according to the gray values of the ground fissure and the location feature of the coal mine area detected in the remote sensing images. The results, compared with supervised classification shows higher accuracy. However, constructing the knowledge characteristics of the ground fissure is a lack of the description of geometric feature, which causes partial ground fissures not to be extracted. Wang et al. (2011) using the enhanced operator of orientation characteristics to extract ground fissures in the goaf based on QuickBird image shown that the results are in good agreement with field surveys. Nevertheless, this method, which is mainly aimed at extracting ground fissures whose linear direction extension is better, is not suitable for the ground fissures with varying directions. Wei et al. (2012) and Wang et al. (2015) used the Unmanned Aerial Vehicle (UAV) image and Thematic Mapper (TM) image to extract the texture features, linear features, fractal dimensions, Normalized Difference Vegetation Index (NDVI) values, and spectral features based on the image pixel, and they built knowledge models according to these features to extract the cracks. However, these two methods do not have a precision validation of their results.

All the researches and methodologies presented above, show a number of issues related to the knowledge characteristics inaccurate mining of ground fissures, weak applicability of the extraction method, lack of robustness verification and low extraction precision in a study of automatic extraction of ground fissures from the remote sensing image. These problems are mainly due to the oneself characteristic of ground fissures. As a linear object, the reason why a ground fissure comes from discontinuity phenomena in the remote sensing image is that there is a weak contrast with its environmental background and it is blocked by vegetation or surrounding objects.

Since 2009, the northeast of Ordos City in Inner Mongolia (China) at about $1300 \mathrm{~m}$ to $1500 \mathrm{~m}$ has been subject to large scale mining (Figure 1). The high strength mining, located in the Lower Cretaceous Dongsheng and Ejinhoro formations, results in serious geological hazards, such as ground fissures and ground collapse (Peng et al., 2016).

Aiming at these problems, our study selects a coal mining area of northeast Ordos (China), as the typical test area, and designs a hierarchical extraction method on the basis of field investigation and visual interpretation results of GeoEye-1 optical remote sensing images. According to the characteristics of the cracks

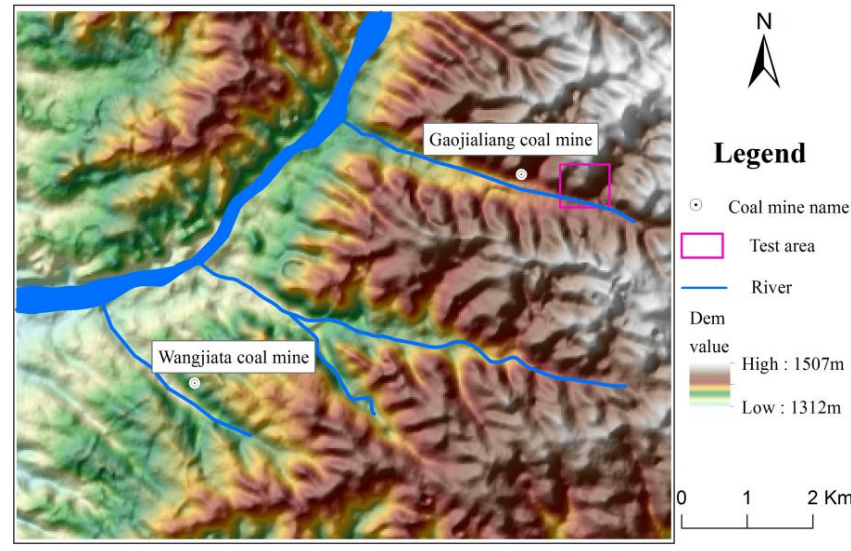

Figure 1. Location of test area. detected in the satellite image, the method achieves accurate and efficient extraction of ground fissures layer by layer.

\section{METHODS}

\subsection{Remote Sensing}

Generally, the width of ground fissures is $0.5-1 \mathrm{~m}$ and remote sensing images with low resolution lose ground fissure information (Fan et al., 2015). For this reason, we used GeoEye-1 satellite whose high resolution $(0.44 \mathrm{~m})$ images meet the requirement of ground fissure identification. Specifically, it has been selected one images acquired in February 2015, i.e. in winter period, when the ground fissure is relatively easy to be identified in satellite images for low vegetation coverage. Before extracting the ground fissures, GeoEye image has been preprocessed: radiometric calibration, atmospheric correction and radiation enhancement. The radiometric calibration uses absolute calibration, which converts the DN value to spectral radiance; the method of atmospheric correction uses ENVI's FLAASH model; Radiation enhancement is beneficial for the display of cracks in remote sensing images. 
In order to verify the reliability of ground fissure extraction results, field sample collection and verification work in the test area have been carried out. Mainly length, width and location of ground fissures identified by remote sensing images have been measured. This allowed to determine the feature threshold and to verify the accuracy of the extraction results. The test area is $0.49 \mathrm{~km}^{2}$ where there are 7 ground fissures, the length of cracks is in the range of $30-70 \mathrm{~m}$, and the width is in the range of $0.4 \mathrm{~m}-0.9 \mathrm{~m}$.

\subsection{The hierarchical method}

This paper designs a hierarchical method to achieve the extraction of ground fissure information in coal mining area. Firstly, according to the known ground fissure information in the experimental area, spectral signatures and geometric features are counted and analyzed. The characteristic parameters involved in the three steps are constantly adjusted to obtain the optimum threshold of features. Then the obtained thresholds are used to extract the ground fissure of the test area hierarchically. Finally, the hierarchical extraction method is applied to the test area to realize automatic extraction of ground fissure information.

The specific technical process has been shown in Figure 2. The extraction method of ground fissure includes mask based on objects, analysis of linear features and analysis of fractal features.

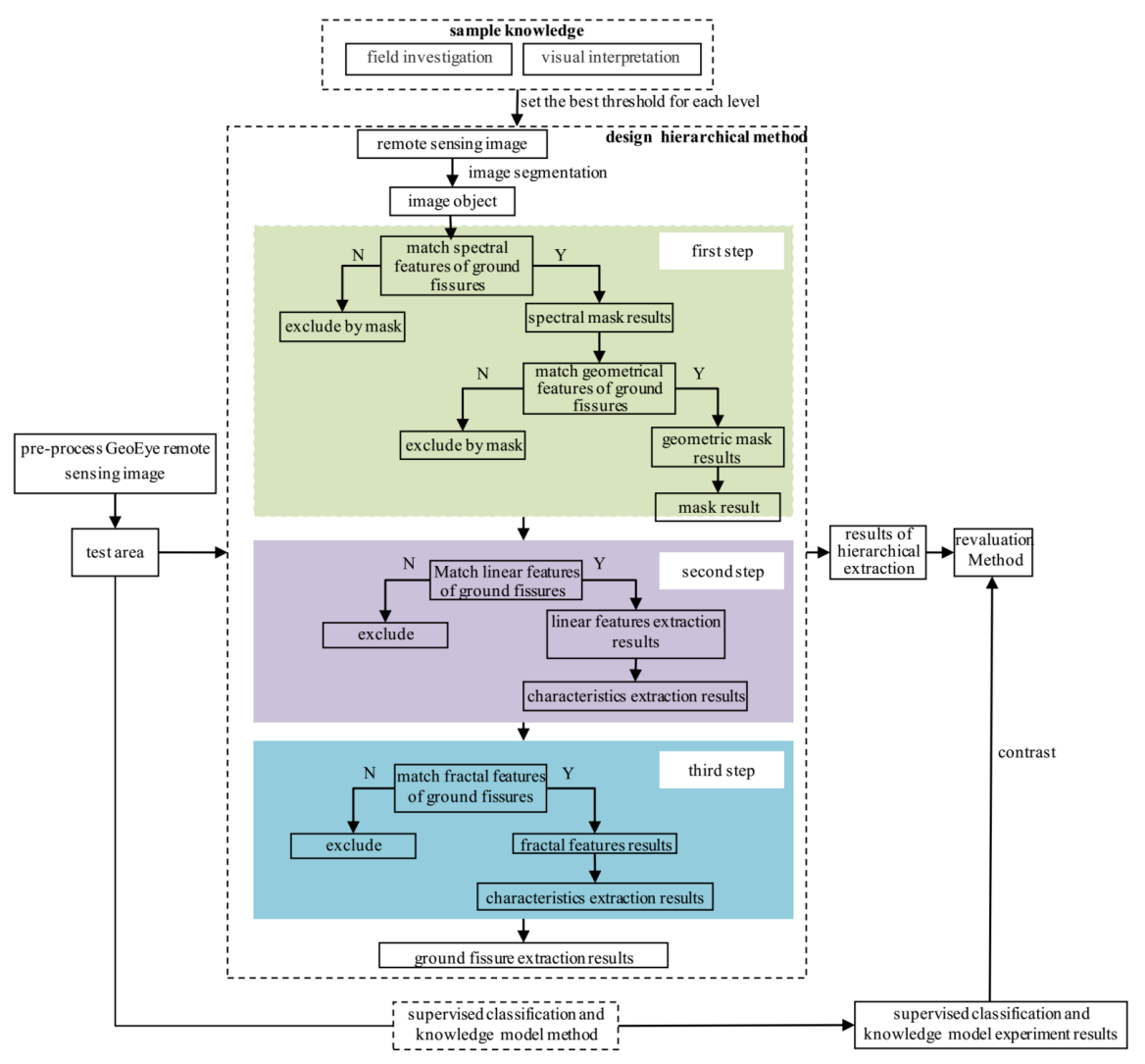

Figure 2. Flow chart of abstracting the ground fissures on basis of remotely sensed image.

Firstly, the remote sensing data is segmented to make the image pixels translate into image objects. On this basis, the hierarchical method is divided into three steps. The first step is that the difference between ground fissures and other ground objects in spectral signatures and geometric features can be used to mask partial surface morphology different from ground fissures. In the extraction process of linear features, the interference from other surface information is eliminated. The second step is that linear features are extracted in canny edge detection method based on results of the first step and surface morphology without linear features are eliminated. The third step is that the fractal dimension of the linear features are calculated and other linear objects that are not ground fissures are removed to extract ground fissure information from the step's result. Thus, the ground fissure extraction from remote sensing image is realized.

In the process of this study, the degree of difficulty about subsequent ground fissure's extraction can be by mask. The incomplete extraction of the ground fissure features can be avoided and algorithm efficiency can be improved. Fractal dimension introduced increases differentiation degrees of ground fissure features and other disturb linear features, and improves the accuracy of ground fissure extraction. 


\subsection{Masking based on object}

Masking based on object is mainly composed of three parts: image segmentation, spectral signatures extraction and geometric features extraction. In this paper, a multi-scale segmentation method is adopted to segment the image (Zhang et al., 2014), which is a bottom-up approach. Neighbor pixels and segmented objects are merged to make the average heterogeneity between objects and objects maximized and the homogeneity of the internal pixels largest. On this basis, spectral features and geometric features are extracted.

\subsubsection{Image segmentation}

Segmentation scale affects the precision of extraction of ground fissures. The final segmentation scale is 50 in the paper by contrasting different scales in the experimental area(Lu et al., 2016). As can be seen from Figure 3, the experimental area is divided too broken when the segmentation scale is 30 . For example, the ground fissures at $\mathrm{a}$ and $\mathrm{b}$ are divided into a number of different objects, which makes the extraction process easy to miss some internal objects and causes incomplete extraction results. When the segmentation scale is 70 , the experimental area is excessively segmented so that the segmented object contains other ground objects, such as the ground fissures at $\mathrm{a}, \mathrm{b}$ where other surrounding objects and ground fissure objects are divided into one and the same, which easily causes ground fissures to be omitted. When the result of segmentation is 50 , the segmentation result of ground fissures is relatively complete. For example, $a, b$ at the ground fissure is relatively complete, which is conducive to completely extract the ground fissures object.
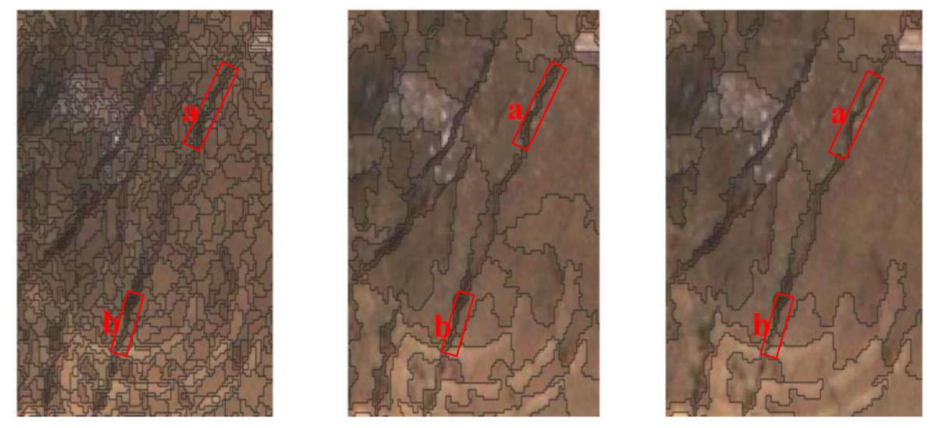

Figure 3. Result of different segmentation scale.

\subsubsection{Spectrum Analysis}

Spectral information is most important and direct to extract texture and shape in remote sensing image classification. Although the ground fissure is not the material object, it is considered that the ground fissure has a certain depth and a narrow width which leads to low reflectance of the light. Therefore, ground fissure usually shows lower brightness on the remote sensing image. The spectral signatures in this study are mainly reflected by the average brightness (Eq. 1) of image objects in different bands. The blue, green, red and near infrared region range of the ground fissure in the GeoEye-1 image are obtained by calculating the average brightness of each object in the experimental area one by one.

$$
\overline{\mathrm{C}}_{i, j}=\frac{1}{m} \sum_{k=1}^{m} C_{i, k}
$$

$\mathrm{C}_{i, k}: k$ pixel values in the $i$ band, $1 \leq \mathrm{k} \leq m, m$ is the number of pixels that constitute the object, $1 \leq \mathrm{i} \leq 4 ; \bar{C}_{i, j}$ : the average reflectance of object $j$ at band $i, 1 \leq \mathrm{j} \leq n, n$ is the number of objects contained in the image.

The reflectance values of every wave band show approximately normal distribution in a certain range of values, and the spectral ranges of ground fissure are determined which are shown in Table 1.

Table 1. Spectral threshold range of ground fissure

\begin{tabular}{clc}
\hline Type & Rule type & $\begin{array}{c}\text { Threshold } \\
\text { value }\end{array}$ \\
\hline & Band1 & $100-380$ \\
Spectral reflectance & Band2 & $350-650$ \\
& Band3 & $680-1000$ \\
& Band4 & $930-1350$ \\
\hline
\end{tabular}

\subsubsection{Geometrical characteristics analysis}

Using the geometric features can recognize the objects with certain morphological features in the image, and the shapes can be described as regular geometric shapes and irregular geometric shapes. Because of the good extension of ground fissure, this paper uses extension cord and roundness to reflect the geometric features of 
ground fissure. Meanwhile, in consideration of the irregular boundary of the ground fissure and the interference of other objects, the compactness is used to reflect the geometrical features of ground fissure. The width of ground fissure in this study is small (about 0.4-0.9 m), which leads to small area. So the area will be one of the geometric features of the ground fissure to improve the extraction accuracy of the ground fissure.

The geometrical features' scopes of the ground fissure in the experimental area are counted and the scope of threshold value of the ground fissure's geometrical features is obtained. The results are shown in Table 2.

Table 2. Geometric feature threshold range of ground fissure

\begin{tabular}{ccc}
\hline Type & Rule type & $\begin{array}{c}\text { Threshold } \\
\text { value }\end{array}$ \\
\hline & Elongation & $>2.5$ \\
Compactness & $<0.2$ \\
& Area & $0.25-30$ \\
& Roundness & $0.042-0.35$ \\
\hline
\end{tabular}

\subsubsection{Mask processing results}

According to the established spectral and geometrical features, this paper adopts mask processing method to remove surface land-form that is against the rule, which can reduce interference for ground fissure's subsequent extraction step. After the mask sequence is adjusted continuously, the first step calculates their spectral statistical character and removes surface morphology beyond spectral range of ground fissures (Section 2.3.2) by masking. The second step calculates the geometric features and the surface morphology of some non-ground fissures is removed by mask rule (Section 2.3.3). On the basis of the masked result, the third step performs hierarchical linear feature extraction.

\subsection{Linear feature analysis}

Linear features are the main features of the ground fissure to differentiate other geological disasters. The linear features in remote sensing images present the features of straight lines or arc lines in the shape(An et al., 2009). Its definition standard is that the straight line or the arc line extends in a specific direction and the length is greater than width which has a small shape index value. There are three main characteristics of linear features in remote sensing images. Firstly, Lineaments are high frequency component in spatial frequency spectrum features. Secondly, spectral features are different from blocks on both sides. Thirdly, the structure of image is represented as edges or lines. Edge detection algorithm is the main method to extract linear features, such as Roberts, Sobel, Log, Canny edge detection operators and so on. Compared with the traditional first-order differential operator, the canny operator is more complex and has large computational complexity(Wu et al., 2014). However, its detection ability and positioning accuracy are better which is suitable to recognize linear features in images. The canny operator guarantees high precision by setting signal noise ratio (SNR) criterion, positioning precision criterion and single-edge response criterion. Therefore, this paper adopts the canny operator to extract linear features from images.

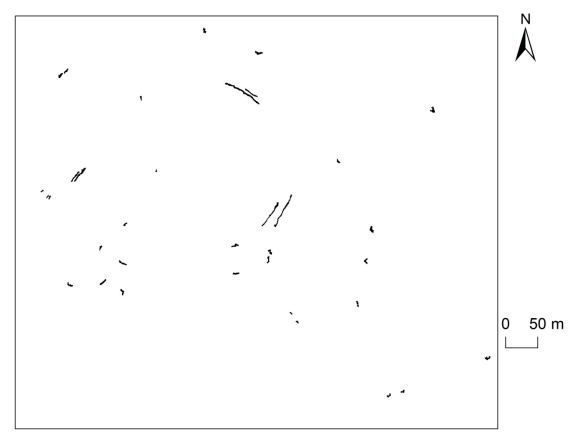

Figure 4. Result of linear feature extraction in test area.

In this study the linear features results (Figure 4) are extracted by mask after the remove of the interference factors in experimental area. On this basis, the fractal features are adopted to determine if the linear features are ground fissures and it is the key factor in the research of the accurate extraction of ground fissures.

\subsection{Fractal features analysis}

Fractal is a general term for the certain similar figures and the structure without any characteristic length. Fractal dimension is its quantitative description (Mandelbrot et al., 1982). The fractal dimension reflects the spatial complexity for remote sensing images, which can distinguish between ground fissures and other linear objects in images. 
There are many methods to calculate the fractal dimension, and among them there is the box counting that is applied early and widely in image processing area (Bisoi et al., 2001). This study adopts the method to calculate the fractal dimension of the extracted linear features (Chen et al., 1993).

The linear feature is extracted by canny edge operator, and fractal dimension is calculated to distinguish the linear feature of non-ground fissure. It is found that fractal dimension of the non-ground fissure in experimental area is less than 0.6, while fractal dimension value of ground fissure is above 0.6. Hierarchical extraction results and accuracy evaluation of ground fissures in test area.

\section{RESULTS OF GROUND FISSURE EXTRACTION}

\subsection{Extraction results and accuracy verification of regional ground fissures}

Based on the hierarchical method, the results of ground fissure extraction are shown in Figure 5. There are a total of 8 cracks extracted in test area where the number of error extraction is 2 , the number of missing extraction is 1 , the number of precision extraction is 6 (extracting the length of cracks is slightly different, but the position is precise). From the results of the extraction, it can be seen that the ground fissure edge continuity that is extracted by the hierarchical method is better, which can keep the extension features of ground fissures.

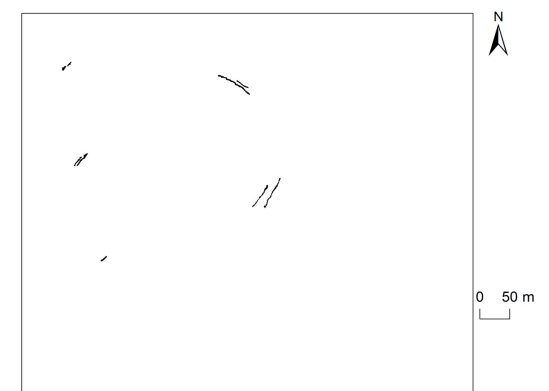

Figure 5. Results of ground fissures extraction.

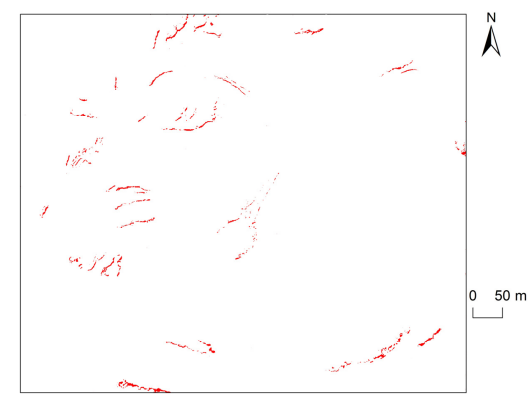

Figure 6. Supervised classification results.

\subsection{Accuracy evaluation}

Based on field investigation and high resolution image visual interpretation results as a reference, this study uses the correct extraction rate and error extraction rate of ground fissures as an accurate evaluation index of ground fissure extraction results. In addition, the results of the ground fissure extraction method have been compared with those obtained by the traditional supervised classification (Figure 6). Table 3 summaries the comparison of ground fissure extraction accuracy assessment. The correct extraction rate of ground fissure and the error extraction rate obtained by supervised classification method are $57.1 \%$ and $85.7 \%$, respectively. By the use of the hierarchical ground fissure extraction method, the correct extraction rate of ground fissure and the error extraction rate amount to $85.7 \%$ and $28.6 \%$, respectively, obviously better than those from the supervised classification results.

Table 3. Accuracy assessment results of ground fissure extraction

\begin{tabular}{|c|c|c|c|c|c|c|}
\hline $\begin{array}{l}\text { Eround } \\
\text { fissure extraction } \\
\text { method }\end{array}$ & $\begin{array}{l}\text { The correct } \\
\text { extraction } \\
\text { number of } \\
\text { ground } \\
\text { fissure }\end{array}$ & $\begin{array}{l}\text { The error } \\
\text { extraction } \\
\text { number of } \\
\text { ground } \\
\text { fissure }\end{array}$ & $\begin{array}{l}\text { Total } \\
\text { number of } \\
\text { ground } \\
\text { fissures } \\
\text { extracted }\end{array}$ & $\begin{array}{c}\text { Total } \\
\text { number of } \\
\text { actual } \\
\text { fissure }\end{array}$ & $\begin{array}{l}\text { Correct } \\
\text { extraction } \\
\text { rate of } \\
\text { ground } \\
\text { fissure }\end{array}$ & $\begin{array}{l}\text { Error } \\
\text { extraction } \\
\text { rate of } \\
\text { ground } \\
\text { fissure }\end{array}$ \\
\hline $\begin{array}{l}\text { Hierarchical ground fissure } \\
\text { extraction method }\end{array}$ & 6 & 2 & 8 & 7 & $85.7 \%$ & $28.6 \%$ \\
\hline Supervised classification & 4 & 6 & 10 & 7 & $57.1 \%$ & $85.7 \%$ \\
\hline
\end{tabular}

* The correct extraction rate and error extraction rate of ground fissure are the ratio of the number of correct, the number of errors to the number of actual. 


\section{CONCLUSIVE REMARKS}

In order to provide a suitable tool for detecting earth fissures in coal-mining regions, we propose an automated hierarchical extraction method, which allows to improve the accuracy of ground fissure automatic extraction on the basis of high resolution satellites optical images, i.e. GeoEye-1. The characteristics of the cracks observed by the satellite image and extracted by the proposed method shows an overall accuracy of $85.7 \%$ consistently higher than that resulting from the traditional supervised classification, which is only $57.1 \%$. Concluding, we can state that our method achieves accurate and efficient extraction of ground fissures and that would be of great utility especially in coal-mining regions, where the monitoring of ground fissures is absolutely necessary to guarantee the safety of the mining operations.

\section{ACKNOWLEDGMENTS}

The authors would like to thank Geological Survey Program of China Geological Survey (DD20160130) and the National Key Basic Research Program of China (No. 2015CB453000).

\section{REFERENCES}

An C J. Du L L, Wang W H, Chen Z P. (2009). Linear feature extraction for SAR image based on fused edge detector. Journal of Electronics \& Information Technology, 31(6):1279-1282. (in Chinese)

Bisoi A K, Mishra J. (2001). On calculation of fractal dimension of images. Pattern Recognition Letters, 22(6-7):631-637.

Chen S S, Keller J M, Crownover R M. (1993). On the calculation of fractal features from images. Pattern Analysis \& Machine Intelligence IEEE Transactions on, 15(10):1087-1090.

Fan L, Zhang X, Xiang M, Zhang H, Shen T and Lin P. (2015). Characteristics of ground fissure development in high intensity mining area of shallow seam in Yushenfu coal field. Journal of China Coal Society,40(6):1442-1447. (in Chinese)

Lu H, Fu X, Li L, Liu C, Bai R and Li N. (2016). Soil and water resources information classification in high resolution images with optimal segmentation scale. Transactions of the Chinese Society for Agricultural Machinery, 47(9):327-333.

Mandelbrot, B. B., \& Wheeler, J. A. (1982). The fractal geometry of nature. Journal of the Royal Statistical Society, 147(4), $468 \mathrm{p}$.

Peng, J., Qiao, J., Leng, Y., Wang, F. and Xue, S. (2016). Distribution and mechanism of the ground fissures in wei river basin, the origin of the silk road. Environmental Earth Sciences, 75(8), 1-12.

Wang Y, Meng S, Li J and Tian L. (2011). Study on remote sensing extraction of cracks information. Northwest Coal, 09(5):31-33. (in Chinese)

Wang, Y. J., Tian, F., Huang, Y., Wang, J. And Wei, C. J. (2015). Monitoring coal fires in Datong coalfield using multi-source remote sensing data[J]. Transactions of Nonferrous Metals Society of China, 25(10):3421-3428. (in Chinese)

Wei C, Wang Y, Wang J and Zhao H. (2012). The technical research of extracting ground fissure information in mining area with the UAV image[J]. Metal Mine, 41(10):90-92. (in Chinese)

$\mathrm{Wu}$ L, Yu X and Huang L. (2014). Edge detection method of remote sensing images based on FCM clustering algorithm and canny operator. Engineering of Surveying and Mapping, 2014, 23(12):1-4.(in Chinese)

Zhang Z J, Li A N, Lei G B, Bian J H and Wu B F. (2014). Change detection of remote sensing images based on multiscale segmentation and decision tree algorithm over mountainous area: a case study in Panxi region, Sichuan Province. Acta Ecologica Sinica, 34(24):7222-7232. (in Chinese)

Zhao W. (2009). Based on the GIS\&RS technology of remote sensing of cracks in the coal mining area in north Shanxi. (Doctoral dissertation, Chang'an University). (in Chinese) 